\title{
"Growing Pain in Children" Review
}

\author{
TAMANNABEGUM ${ }^{1}$, SOOFIA KHATOON ${ }^{2}$
}

\section{Introduction:}

Growing Pain (GP) was first described in the early century by French physician Marcel Duchamp1. Although the topic of many reports since that time and despite being a frequent Pediatric clinical presentation, growing pains remains largely misunderstood ${ }^{1,2}$.

Growing pains (GP) is the most common form of episodic childhood musculoskeletal pain ${ }^{1,2}$. Medical science is still unable to fully explain the exact causes of the discomfort experienced by up to one -third of all children at some time during early childhood. 1,2,3 The Hallmark of growing pain, first it always affects both legs, always gone in morning. ${ }^{3}$. It is very common and easy to diagnose once the typical clinical characteristics are presented. The natural history is benign with disappearance of most attacks of pain by adolescence. However it is not clear whether some of these children develop symptoms of other noninflammatory pain syndromes ${ }^{2,4}$.

In this review described the clinical presentation, pathogenesis, causes, natural course, and alleviating the family's anxiety.

Definition: According to Dr. William Feldman growing pain is definite, pain occurs in both legs usually around bed time. It can usually be made better by rubbing the legs or giving a little acetaminophen. Typically, growing pain occur at night while a child is off his feet and in bed ${ }^{3}$.

Features of growing pain includes as follows $\mathbf{s}^{1,3,4,5}$

Age: GP occurs in children in two age groups: from 3 to 5 years, and8 to 10 years.

Daily Pattern: Growing pain tends to occur in late afternoon or evening and will occasionally wake a child at night. They are often experienced after a busy active day. Some children get the pain every night, some once a week or so, and others only occasionally.

1. Associate Professor, Department of Paediatrics, Shahid Suhrawardy Medical College and Hospital, Dhaka.

2. Professor and Head of the Dept of Paediatrics, Shahid Suhrawardy Medical College and Hospital, Dhaka.

Correspondence: Dr. Tamanna Begum
Intensity: The pains are generally mild; however, a few children complain of severe pain. The pain can be brief, lasting a few minutes, or it can last for an hour or longer. By morning the child is almost always pain free. GP is episodic, with pain-free intervals from days to months. In severe cases the pain can occur daily and nature of pain are sharp and throbbing

Location: Growing pain affect muscles and not joints. Most children report that the pain is in front of the thighs, in the calves, or behind the knee. They almost always affect both limbs. The "growing pains" joint looks quite normal. There are no objective signs of inflammation on physical examination.

Relieving Factors: This pain can generally be relieved by massages. Children who have pain from other causes often do not like to be touched, because movement can increase the pain. Almost always painfree by next morning.

\section{Why do some kids get growing pains while others do not?}

As already mentioned previously, the causes of growing pain are not very obvious. The proposed causes according to Dr.Yosef Uziel and Dr. Philip J Hashkes ${ }^{4,5}$ are

1. Low pain tolerance: Kids with growing pain exhibited a lower pain tolerance when compared to controls.

2. Over use: Kids who reported growing pain were overactive, when compared to other kids. Also parents note that when a kid has had an exhausting day, they more likely to complain.

3. Bone strength density: Children suffering from growing pain are found to have a low bone strength density. This along with overuse and hyperactivity is likely to cause pain.

4. Mechanical strains: Many children with growing pain are found to have flat foot with mild outward turning of back of foot. This could cause increased strain during activity leading on to pain. 
5. Although the quality of life is similar to other kids, it is suggested that family environment, stress and psychological disposition often can contribute to pain. Parents note that the kid is more likely to complain of pain, when he has been mentally upset. .

\section{What is not growing pain?}

It is very important not to miss any disease which also can present as leg pain. The following are the warning signs that clue that the pain is not just a 'growing pain'.

1. If the pain is persistent or occurs even during daytime.

2. If the pain is increased on handling or movement. In growing pain, the child is comforted by massaging.

3. If the pain is localized in a joint, other diagnosis such as childhood arthritis should be considered, as growing pains practically never affect joints.

4. If the child develops a limp while walking.

5. If the child runs a temperature, it may signal infection and will need a thorough check up and tests.

6. If the child has or develops a rash.

7. If the child develops pain in only one leg consistently or if there is a wound, bruise or redness.

8. Limb weakness.

Prevalence of growing pain.

The prevalence of GP ranges has been reported from 1928.It ranges from as little as $2.6 \%$ to $49 \%$ of children 2,3 . Oster found that as many as $15 \%$ of school-age children have occasional limb pain 2,3 and recently Evans and Scutter in a very large community study in Australia reported a prevalence of $37 \%$ in children aged $4-6$ years ${ }^{7}$. GP mainly affects children between the ages of 3-12 years. Prevalence of recurrent leg pains, often described as "growing pains" in children 4 to 6 years of age in South Australia.. The prevalence estimate obtained was 36.9\% (95\% $\mathrm{Cl}, 32.7-41.1){ }^{3,4}$.

\section{Possible causes $2,4,5$}

Causes of these pains are unclear. The pain may be due to:

Muscular tiredness - more physical activity than usual can be linked to more aching muscles for some children.
Poor posture - standing, sitting or walking awkwardly puts greater than usual strain on the supporting muscles of the body. Sometimes children whose feet roll in (with very flat feet) may have more trouble with pains than other children.

Emotional upset - stress or unhappiness may trigger aches and pains.

Overweight-Children with growing pain have significantly greater body weight (about $5 \%$ heavier)

Pathogenesis: 2, 4, 8.9.10.11

The etiology of GP is unknown. Very few studies have been done to elucidate the etiology and pathogenesis of this common syndrome.

Low pain threshold: GP due to the non-inflammatory musculoskeletal pain syndromes are associated with a lower pain threshold. ,. Hypothesis was that the pain threshold in children with GP is lower compared to controls ${ }^{14}$. It was interesting to note that the pain threshold at the anterior tibia was the highest in the body, including among children with GP. This is the region most commonly reported by children with GP as painful during attacks ${ }^{15}$.

Bone strength: GP usually occurs late in the day and is often reported on days of increased activity, GP may represent a relative local overuse (stress) syndrome, and may be associated with decreased bone strength 16,17 . Thus GP may represent a local lower extremity overuse syndrome with bone fatigue in children with low pain thresholds,

Blood perfusion changes: The sudden onset and severity of GP as well as the transience of the attacks support a hypothesis that GP has a vascular perfusion component, similar to migraines. Furthermore a higher prevalence of GP was found among children with migraine headaches ${ }^{18,19}$.

Anatomical/Mechanical: Many clinicians have an impression that many children with GP are hypermobile, In addition, fibromyalgia was resulting in pain from a low pain threshold ${ }^{19.20}$. Other mechanical issues associated with hypermobility include flexible flat feet with hind foot valgus. This mechanical instability might be a cause of GP in some children. In one small controlled trial shoe inserts were effective in reducing the frequency and severity of $\mathrm{GP}^{20}$.

Family environment: Naish and Apley assumed that emotional disturbances are more common in children with GP ${ }^{4,20}$. Oberklaid et al, has shown in his studied, children with musculoskeletal pains, suggesting a psychosocial contribution to their pain ${ }^{20}$. 


\section{Investigations and diagnosis:}

Correct diagnosis of GP requires a thorough history and physical examination. Currently, the diagnosis is based only on typical clinical symptoms and exclusion criteria. There are no sensitive or specific laboratory tests ${ }^{2,3,6}$. When patients have typical clinical characteristics there is no need to do any unnecessary laboratory investigation or imaging tests. However, if the symptoms are atypical, the diagnosis of GP should not be assumed without evaluating other causes.

\section{Treatment of growing pain:}

The most important intervention is to explain the natural benign course of the GP. Current treatment is reassurances to the children and their family, thus decreasing anxiety and fear. GP may have an impact on the child and family, especially among children with frequent nocturnal attacks. Following measures are taken.

Massage: Locally massage the aching area, during pain episodes

Apply a heating pad to the area-warm bath and water bath

Help the child gently stretch and flex the area until the pain passes.

Medication: Some children need acetaminophen and non-steroidal anti- inflammatory drugs (NSAID). but do not prescribe aspirin ${ }^{9,11}$. The calcium intake in GP patients with lower bone strength group was relatively low. It is possible that a diet enriched in calcium and vitamin D might affect bone status and pain episodes, but this theory was not investigated.

\section{Conclusions and future studies:}

GP is a frequent problem in Pediatrics practice. Physicians should be careful to adhere to clear clinical criteria of growing pain as some times it was overdiagnosed and unnecessary investigation was done and treated as rheumatic fever for years together Further studies into the pathogenesis of GP should be performed. Further larger and genetically homogenous studies are required.

\section{References:}

1. Uziel1 $\mathrm{Y}$ and Hashkes PJ. Growing pains in children. Pediatric Rheumatology 2007; 5: 1-8.

2. Evans AM Growing pains: contemporary knowledge and recommended practice. Journal of Foot and AnkleResearch : 2008; 1-5

3. Nell. DB. Growing pains in Children. The Parent report. com 2010; 05: 1-3.
4. www.betterhealth.vic.gov.au:Growing pain-better health channel 2010; 1-2

5. De Inocencio J: Epidemiology of musculoskeletal pain in primary care. Arch Dis Child 2004; 89(5): 431-4.

7. Evans AM, Scutter SD: Prevalence of "growing pains" in young children. J Pediatr 2004; 145(2): 255-8.

8. Hashkes PJ, Friedland O, Jaber L, Cohen HA, Wolach B, Uziel Y Decreased pain threshold in Children with growing pains Journal of Rheumatology 2004; 31(3): 610-13.

9. Manners P: Are growing pains a myth? Aust Fam Physician 1999; 28(2): 124-7.

10. Friedland O, Hashkes PJ, Jaber L, Cohen A, Eliakim A, Wolach B, Uziel Y: Decreased bone strength in children with growing pains as measured by uantitative ultrasound. J Rheumatol 2005; 32(7): 1354-7.

11 Aromaa M, Sillanpaa M, Rautava P, Helenius H: Pain experience of children with headache and their families: a controlled study. Pediatrics 2000; 106(2): 270-5.

12. Evans AM: Relationship between growing pains and foot posture in children: single case experimental designs in clinical practice. J Am Podiatr Med Assoc 2003; 93(2): 111-17.

13. Palermo TM: Impact of recurrent and chronic pain on child and family daily functioning: a critical review of the literature. J Dev Behav Pediatr 2000; 21(1): 58-69.

14. Uziel $Y$, Friedland $O$, Jaber L, Press J, Buskila D, Wolach B, Hashkes PJ: Living with children with growing pains: How does it affect the parents? J Musculoskel Pain 2007; 15: 1-2.

15. Rajaram SS, Walters AS, England SJ, Mehta $D$, Nizam F: Some children with growing pain may actually have restless leg syndrome. Sleep 2004; 27(4): 767-73.

16. Oberklaid F, Amos D, Liu C, Jarman F, Sanson A, Prior M. "Growing Pains": clinical and behavioral correlates in a community sample. $J$ Dev Behav Pediatr 1997; 18(2): 102-6

17. Smith FG. Growing pains, parent and children need reassuring about this self limiting condition of unknown cause BMJ 2006; 2: 1-4.

18. http// www.hubpage.com.. Diva Growing pains in Children ; 986; 1-3.

19. Lowes RM and Haskes PJ. Growing pains: a non inflammatory pain syndrome of early childhood. Nat Clin Pract Rheumtol 2008; 4(10): 542-9. 